\title{
Importância do conhecimento sobre saúde bucal dos cuidadores de pacientes com necessidades especiais
}

\author{
Importance of oral health knowledge of \\ caregivers of patients with special needs
}

\author{
César Emmanuel Borges Castro ${ }^{1}$ \\ Gislaine Ribeiro de Oliveira Margon da Rocha ${ }^{2}$ \\ Paula FrassinetI Guimarães de SÁ ${ }^{3}$ \\ Cláudio Maranhão Pereira ${ }^{4}$
}

\begin{abstract}
RESUMO
Objetivos: Analisar o conhecimento de mães e/ou cuidadores de PNE em relação à higienização e aos cuidados relacionados à saúde oral de seu(s) filho(s) e determinar as principais dificuldades apontadas pelos entrevistados em relação à sua manutenção.

Material e Métodos: Os participantes foram avaliados por meio de um questionário constituído por 10 perguntas, de múltipla escolha, entregue aos cuidadores e/ou mães de PNEs, matriculados no Centro de Ensino Especial 01, em Brasília-DF.

Resultados: Apesar dos resultados positivos em relação ao conhecimento de mães e/ou cuidadores em relação às rotinas de higienização e cuidados com a saúde oral do PNE, o nosso estudo aponta que ainda existem algumas lacunas a serem consideradas, no âmbito da prevenção e da promoção da saúde bucal. $\mathrm{Na}$ amostra analisada, houve aqueles que não levaram o seu(ua) filho(a) a consulta alguma odontológica no ano anterior e aqueles que nunca participaram de qualquer atividade educativa ou treino para auxiliar o PNE com a higienização oral.

Conclusão: A demanda por atendimento odontológico é crescente no grupo de PNE, cabendo aqui ressaltar que a saúde bucal permeia um dos direitos fundamentais garantidos pela nossa Constituição. Assim, a real implantação do Plano Nacional dos Direitos das Pessoas com Deficiência na rede de assistência pode contribuir significativamente para que equipes de Atenção Primária e os Centros de Especialidade Odontológicas possam atuar com os cuidadores, além de atender adequadamente ao PNE.
\end{abstract}

Palavras-chave: Cuidadores. Saúde bucal.

\begin{abstract}
Objective: The present study had as its principal/main objective/target, analyse the knowledge of mothers and/or caretakers of the PNE about oral/dental hygiene and the care related to the oral/dental health of their children and to determine the main difficulties indicated and pointed out by the interviewees referring to its maintenance.

Material and Methods: The participants were evaluated by means of a multiple choice questionnaire containing 10 questions given to the caretakers and/or mothers of the PNE enrolled in the Centro de Ensino Especial 01 (Special Teaching Centre 01), in Brasília-DC.

Results: Regardless of the positive results relative to the knowledge of mothers and/or caretakers referring to the routines of hygiene and care of oral/dental care/health of the PNE, our study indicates there are gaps to be considered about the prevention and the promotion of buccal health care. In the analysed examples/ samples there were those who had not taken their children to an odontology appointment/visit the previous year and there were those who had never participated in any educational activity or training to assist the PNE with buccal hygiene.

Cirurgião-dentista graduado pelo curso de Odontologia da Universidade Paulista, Brasília/DF, Brasil.

Mestre em Ciências da Saúde - UnB, Professor Adjunto do curso de Odontologia da Universidade Paulista, Brasília/DF, Brasil.

3 Doutorado em Química/ University of Rhode Island, Estados Unidos, Professor Adjunto do curso de Odontologia da Universidade Paulista, Brasília/DF, Brasil.

4 Doutor em Estomatopatologia - FOP/UNICAMP, Professor Titular de Estomatologia da Universidade Paulista, Brasília/DF, Brasil.
\end{abstract}


Conclusions: The demand for odontology services are ever growing in the PNE group, thus reiterating the fact that buccal care/health permeates one of the fundamental rights warranted/assured by our Constitution. Thus, the real implementation of the Plano Nacional dos Direitos da Pessoas com Deficiência (National Plan for the Rights of Persons with Deficiencies) in the assistance network may significantly contribute for the teams of Primary Attendance and the Centros de Especialidade Odontológica (Special Odontology Centers).

Keywords: Caregivers. Oral health.

\section{INTRODUÇÃO}

Segundo dados do último censo, atualmente a população brasileira tem aproximadamente 260 milhões de habitantes. Entre estes, estima-se que $23,9 \%$ apresentam algum tipo de deficiência seja ela visual, auditiva, motora e intelectual. Esses indivíduos são coletivamente designados como Pessoas com Necessidades Especiais. ${ }^{1}$ Estima-se que eles representam $10 \%$ da população mundial. ${ }^{1,2}$

Dessa forma, a terminologia Pessoa com Necessidade Especial (PNE) é utilizada para se referir ao indivíduo com alterações físicas, mentais ou sociais, podendo estas serem consideradas simples ou complexas, crônicas ou agudas, necessitando assim de um atendimento prioritário com princípios especiais em função dos agravos decorrentes do seu quadro de saúde. ${ }^{3}$

O PNE necessita de uma atenção maior por parte de seus cuidadores. Muitas das vezes, esse papel é desempenhado pela mãe, a qual assume a responsabilidade direta nos cuidados para com o indivíduo ao longo de toda a sua vida. A rotina diária dos cuidadores depende muito do grau de limitação que o PNE apresenta. Para os de maior complexidade, é exigida uma rotina diária mais intensa devido às consultas agendadas, medicações, cuidados pessoais, entre outros. ${ }^{4}$

Devido a suas limitações, o grupo de PNE é considerado um grupo com alto índice de vulnerabilidade a desenvolver cáries e doenças periodontais, por causa de dificuldades na higienização bucal. A dieta alimentar, normalmente rica em carboidratos, também é um fator que pode contribuir para a evolução desses agravos. Vale ressaltar também a higiene oral negligente por parte de seus cuidadores, favorecendo assim o acúmulo maior de placa bacteriana vindo a ocasionar essas patologias. Assim, o atendimento odontológico deve ser feito sempre em conjunto, respeitando as limitações do paciente, dando atenção aos cuidadores e os incentivando sobre a importância da saúde bucal dos indivíduos com necessidades especiais. $^{5}$

A Resolução $n^{\circ}$. 25/2002, publicada pelo Conselho Federal de Odontologia, regulamentou a especialidade de Odontologia para Pacientes com Necessidades Especiais. A intenção da norma foi estabelecer os critérios de capacitação de Cirurgiões-Dentistas para o atendimento de pessoas que necessitam de cuidados odontológicos especiais. ${ }^{6}$

$O$ ato de cuidar muita das vezes não é uma lição fácil, devido aos fatores determinantes do PNE. A mudança da rotina dos cuidadores ocorre repentinamente, demandando assim de uma boa orientação em saúde, para um completo bem-estar dos mesmos.

Dessa forma, a importância em orientar tanto os familiares, quanto os cuidadores sobre a higiene em saúde bucal é crucial para a manutenção e o bem-estar geral do PNE. Com frequência, devido às limitações que muitos apresentam, existe a necessidade do uso prolongado de mamadeira, oferta de alimentos ricos em açúcares, alimentação pastosa, uso rotineiro de medicamentos com alto teor de sacarose ou medicamentos que causam xerostomia, deglutição prejudicada, malformação dentária e oclusal. Todos esses são fatores condicionantes que dificultam 
a manutenção de padrões adequados de higienização bucal. ${ }^{7}$

O presente estudo teve como principal objetivo analisar o conhecimento de mães e/ou cuidadores de PNEs matriculados no Centro de Ensino Especial 01 de Brasília, em relação à higienização e aos cuidados relacionados à saúde oral de seu(s) filho(s) e também determinar as principais dificuldades apontadas pelos entrevistados em relação à manutenção da saúde bucal.

Nesse contexto, esta pesquisa torna-se importante, pois busca identificar as condições de saúde bucal de PNE e também determinar as principais dificuldades apontadas pelos cuidadores, em especial, e as mães para a manutenção da saúde oral de seus filhos. Com isso, os dados ora coletados podem contribuir para a elaboração de ações em saúde no âmbito da promoção, da prevenção e do tratamento dos PNEs, facilitando, assim, a assistência prestada aos mesmos. Por conseguinte, essas ações podem reduzir o número de agravos à saúde bucal mais frequentes nesse grupo de indivíduos, como é o caso da cárie e das alterações periodontais.

\section{MATERIAL e mÉtodos}

Um questionário constituído por 10 perguntas foi entregue aos cuidadores e/ou mães de pessoas com necessidades especiais, matriculadas no Centro de Ensino Especial 01, em Brasília-DF, com intuito de analisar o conhecimento dos entrevistados sobre a importância da higiene bucal, identificando também os fatores de risco mais comuns no grupo de PNE.

A seleção dos participantes foi ancorada de acordo com o seguinte critério de inclusão: homensemulheres, maioresde18anosdeidade, com filhos ou PNE sob a sua responsabilidade, que estivessem regularmente matriculados no CEE 01. Os participantes deveriam concordar em participar da pesquisa, sendo tal anuência concedida por meio da assinatura do Termo de Consentimento Livre e Esclarecido (TCLE). Como critério de exclusão foi considerado que indivíduos, com qualquer grau de parentesco, cuidadores ou amigos sem responsabilidade legal pelo PNE não estariam aptos a participar do estudo.

O questionário foi constituído com as seguintes perguntas:

1. Em qual das faixas-etárias a seguir o(a) seu(ua) filho(a) se enquadra?

( ) 14-19 anos

( ) 20-29 anos

( ) 30-39 anos

( ) 40-49 anos

( ) Acima de 50 anos

2. Com qual frequência, no último ano, o(a) seu(ua) filho(a), foi ao dentista?

( ) Nenhuma vez

( ) 1 vez/ano

( ) 2 vezes/ano

( ) 3 vezes/ano

( ) Mais de 3 vezes

3. De um modo geral, como o(a) senhor(a) avalia a saúde bucal de seu(ua) filho(a)?

( ) Ótima
( ) Boa
( ) Ruim
( ) Péssima

4. Quantas vezes ao dia, o (a) seu(ua) filho(a) realiza a higiene oral (escovação e uso de fio dental)?

( ) Nenhuma vez

( ) $1 \mathrm{vez} / \mathrm{dia}$

( ) 2 vezes/dia

( ) 3 vezes/dia

( ) Mais de 3 vezes/dia

5. O senhor(a) auxilia seu filho(a) durante a higienização oral (escovação e utilização do fio dental)?

( ) Sim
( ) Não
( Às vezes

6. Quais são as dificuldades encontradas pelo(a) senhor(a) ao auxiliar e/ou realizar a higienização oral de seu(ua) filho(a)?

( ) O posicionamento da escova de dente

( ) O uso do fio dental 
( ) A falta de tempo

( ) Medo de machucar ou de causar algum dano

( ) Insegurança por não saber se está realizando o procedimento de forma correta

( ) Não tenho qualquer dificuldade

7. Na sua opinião, o que facilitaria a manutenção de uma boa saúde bucal do(a) seu(ua) filho(a):

( ) Maior número de centros especializados disponibilizados pela rede pública

( ) Maior número de profissionais disponibilizados na rede pública

( ) Menor custo de tratamento das clínicas privadas

( ) Maior acesso a informações sobre higiene oral e prevenção

( ) Orientação e treinamento de como realizar uma boa higiene oral

( ) Outros:

8. Quais problemas descritos a seguir o(a) senhor(a) reconhece como sendo causado pela má higienização oral?

( ) Cárie

( ) Placa bacteriana

( ) Mau hálito

( ) Necessidade de extração dentária

( ) Inflamação da gengiva

( ) Problemas cardíacos

( ) Problemas renais

9. $O(A)$ senhor(a) sabe que a rotina alimentar tem grande influência na saúde dos dentes do seu(ua) filho(a)?

( ) Sim

( ) Não

10. $\mathrm{O}(\mathrm{A})$ senhor(a) já participou de palestras educativas sobre técnicas de escovação?

( ) $\operatorname{Sim}$

( ) Não

Os dados coletados foram organizados, tabulados, agrupados e analisados separadamente, de acordo com os resultados obtidos para cada uma das variáveis estabelecidas no instrumento de coleta, utilizando o programa Microsoft Excel, em uma análise quantitativa dos dados, devido ao número reduzido de entrevistados.

Antes do início da pesquisa, o projeto foi submetido, analisado e aprovado pelo Comitê de Ética da Universidade do Distrito Federal - UDF, conforme determinado na Resolução
466/12 do CNS/MS. A aprovação foi obtida por meio do Parecer 2.278.267, exarado em 15 de setembro de 2017. Os participantes foram instruídos sobre o caráter não obrigatório de sua participação, sendo a sua participação condicionada à assinatura do TCLE.

\section{Resultados}

Um resumo do perfil dos participantes é apresentado na Tabela 1. Na tabela, foram avaliadas respostas fornecidas por 30 mães e/ ou cuidadores de alunos do Centro Especial 01 de Brasília-DF, desses, 28 categorizados como pais e 2 como cuidadores.

Tabela 1: Perfil dos entrevistados.

\begin{tabular}{ccc}
\hline & $\begin{array}{c}\text { Gếnero } \\
\text { Masculino }(\boldsymbol{n})\end{array}$ & $\begin{array}{c}\text { Gềnero Feminino } \\
(\boldsymbol{n})\end{array}$ \\
\hline Pais & $10(33,33 \%)$ & $18(60 \%)$ \\
\hline Cuidadores & 0 & $2(6,66 \%)$ \\
\hline Total & $10(33,33 \%)$ & $20(66,66 \%)$
\end{tabular}

Um panorama da distribuição etária dos alunos, cujos cuidadores são responsáveis, é apresentado na Figura 1. Apesar de uma distribuição equitativa entre o grupo de indivíduos, cuja idade varia entre 14-49 anos, dois terços deles encontram-se entre 20-49 anos. Destes, o maior percentual acha-se na faixa etária entre 20-29 anos. O número de adolescentes corresponde a $23 \%$ da amostra.

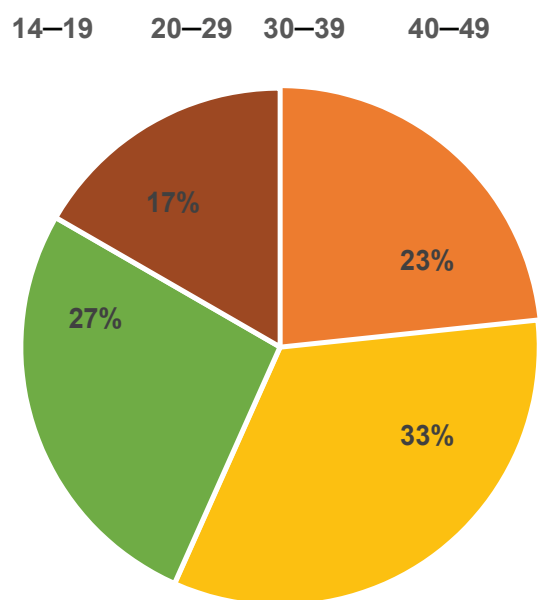

Figura 1: Distribuição etária dos alunos. 
A Figura 2 apresenta a distribuição da frequência, no último ano, a consultas odontológicas realizadas pelo(a) filho(a) dos entrevistados. Somente quatro entrevistados, $13 \%$, alegaram não terem realizado qualquer visita a esse profissional. Mais de um terço deles informaram que realizara duas visitas $(33 \%)$, sendo valor semelhante observado para aqueles que fizeram, pelo menos, uma visita ao dentista (27\%). Cinco alunos, o que corresponde a $10 \%$ da amostra, foram a mais de três consultas.

A percepção da saúde bucal dos alunos, pelo cuidador, foi considerada como ótima ou boa por $27 \%$ e $40 \%$ dos entrevistados, respectivamente. Somente um entrevistado avaliou a saúde bucal de seu filho como ruim. Os demais, $30 \%$ dos entrevistados, a consideraram como regular.

Os resultados encontrados em relação à frequência diária da prática de higienização oral por pais e/ou cuidadores de PNE mostraram que $44 \%$ dos entrevistados a realizam três vezes ao dia, sendo que $20 \%$ o fazem mais de três vezes. Somente $3 \%$ dos participantes a realizam uma vez ou não a realizam. Cerca de um terço dos entrevistados efetuam a higiene oral de seu(ua) filho(a) duas vezes ao dia.

Quanto ao auxílio durante a higienização oral dos alunos (escovação e uso de fio dental), constatou-se que $77 \%$ das mães e/ou cuidadores auxiliam durante a higienização, e que $23 \%$ dos entrevistados, às vezes, realizam esse auxílio. Nenhum dos entrevistados respondeu que não auxilia o(a) filho(a) durante a higienização oral.

Quando questionados sobre as dificuldades encontradas para a realização da higiene oral dos PNEs, as mães, e/ou cuidadores, relataram $(10 \%)$ que têm dificuldade no posicionamento da escova de dente, $35 \%$ no uso do fio dental, $7 \%$ não o fazem por medo de machucar ou de causar algum dano, $17 \%$ por insegurança por não saber se está realizando o procedimento

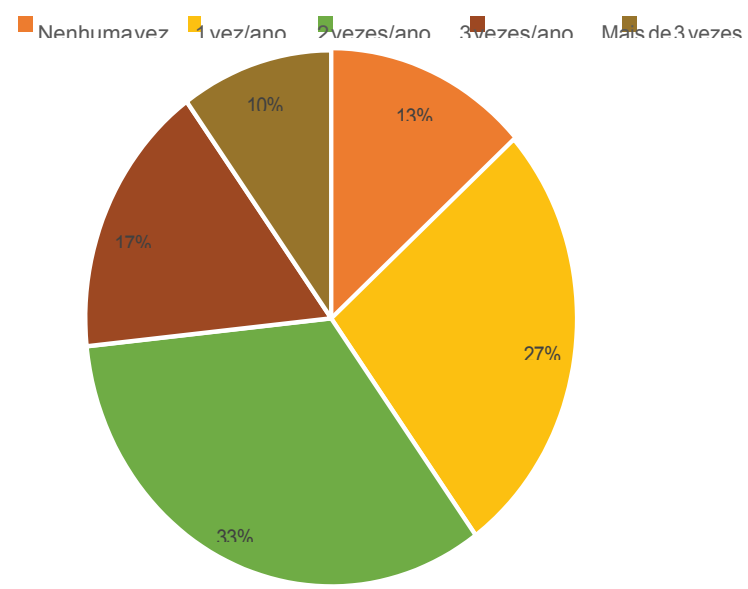

Figura 2: Frequência de consultas ao dentista no último ano.

de forma correta, $28 \%$ relataram não ter dificuldade na realização e $3 \%$ não o fazem pela falta de tempo (Figura 3).

Em relação à questão sobre o que facilitaria a manutenção de uma boa saúde bucal de seus filhos, onze entrevistados (36\%) acreditam que um maior número de centros especializados disponibilizados pela rede pública seria a melhor opção, enquanto sete responderam que um maior número de profissionais disponibilizados na rede pública poderia ser uma alternativa. O mesmo número de entrevistados (5) acredita que o maior acesso a informações sobre higiene oral, prevenção e orientação, bem como, treinamento de como realizar uma boa higiene oral poderia contribuir para uma melhoria da saúde bucal de seu(ua) filho(a). Somente dois entrevistados apontaram que o menor custo de tratamento das clínicas privadas seria uma boa opção.

Quantos aos problemas relacionados à má higienização oral, $40 \%$ das mães e/ou cuidadores indicaram a cárie como sendo o maior problema decorrente da higienização oral precária. Outros problemas apontados foram a placa bacteriana (27\%), a inflamação da gengiva (20\%), o mau hálito (10\%), e 


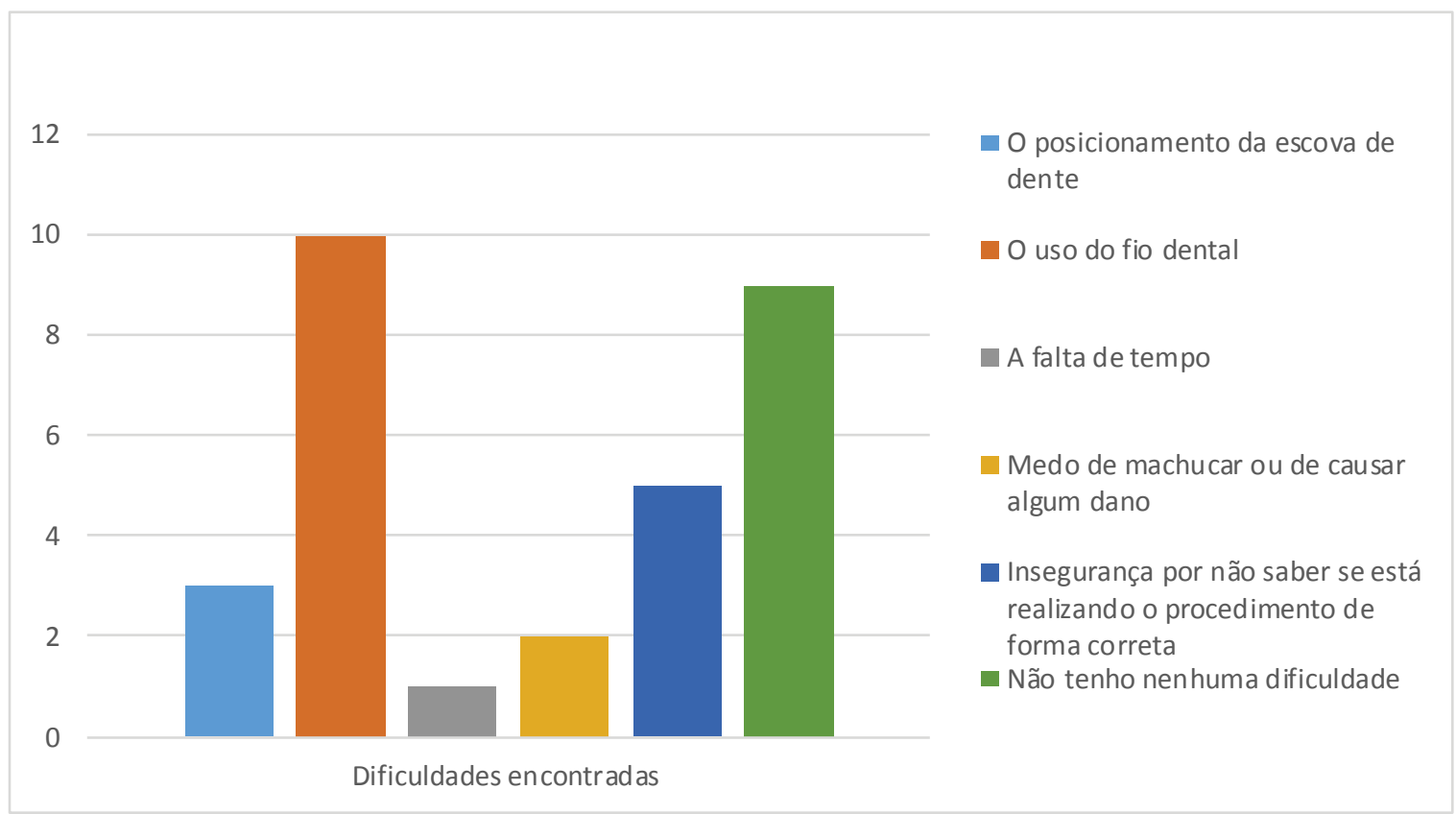

Figura 3: Dificuldades encontradas para a realização da higiene oral dos PNEs.

a necessidade de extração dentária (3\%). Nenhum dos entrevistados apontou problemas cardíacos ou renais como consequência ou associados à má higienização oral (Figura 4).

Do total de entrevistados, $90 \%$ sabem que a alimentação pode causar danos na saúde oral dos PNEs. Os demais relataram que não sabem se essa poderia influenciar na saúde dos mesmos. Por fim, ao serem questionados sobre a participação em palestras educativas acerca de técnicas de escovação e medidas associadas à saúde oral dos PNEs, $67 \%$ relataram que já participaram dessas atividades.

\section{Dıscussão}

Segundo a Organização das Nações Unidas (ONU) há mais ou menos cerca de 600 milhões de PNEs no mundo, sendo que $20 \%$ dessa população vive em países desenvolvidos. Assim, muitos desses indivíduos são considerados de baixa renda e que apresentam níveis de escolaridade classificados como baixos. No Brasil, aproximadamente $1 / 4$ da população tem, ou apresenta, algum tipo de deficiência. ${ }^{8,9}$

$\mathrm{O}$ ato de cuidar do PNE pressupõe a execução de atividades diversas. Considerando o grau de dependência da pessoa que recebe o cuidado, a demanda vai desde cuidados básicos com a higiene e alimentação até outros mais complexos, como sondagem e cuidados com dispositivos de saúde. ${ }^{4}$

É sabido que a higienização oral adequada previne diversos problemas odontológicos e outros agravos deles decorrentes. Vários fatores, além da restrição e falta das habilidades necessárias para promover uma correta higiene oral leva, muitas vezes, o PNE à perda dentária. Além disso, no âmbito da saúde bucal, distintos fatores contribuem para a precariedade dos serviços ofertados. Estudos apontam que, além da ansiedade e da apreensão por parte dos familiares, ainda existe uma resistência de muitos profissionais de saúde para atender ao PNE. Essa pode ser atribuída à falta de conhecimento, confiabilidade, treinamentos adequados, sensibilidade ou, muitas vezes, a 


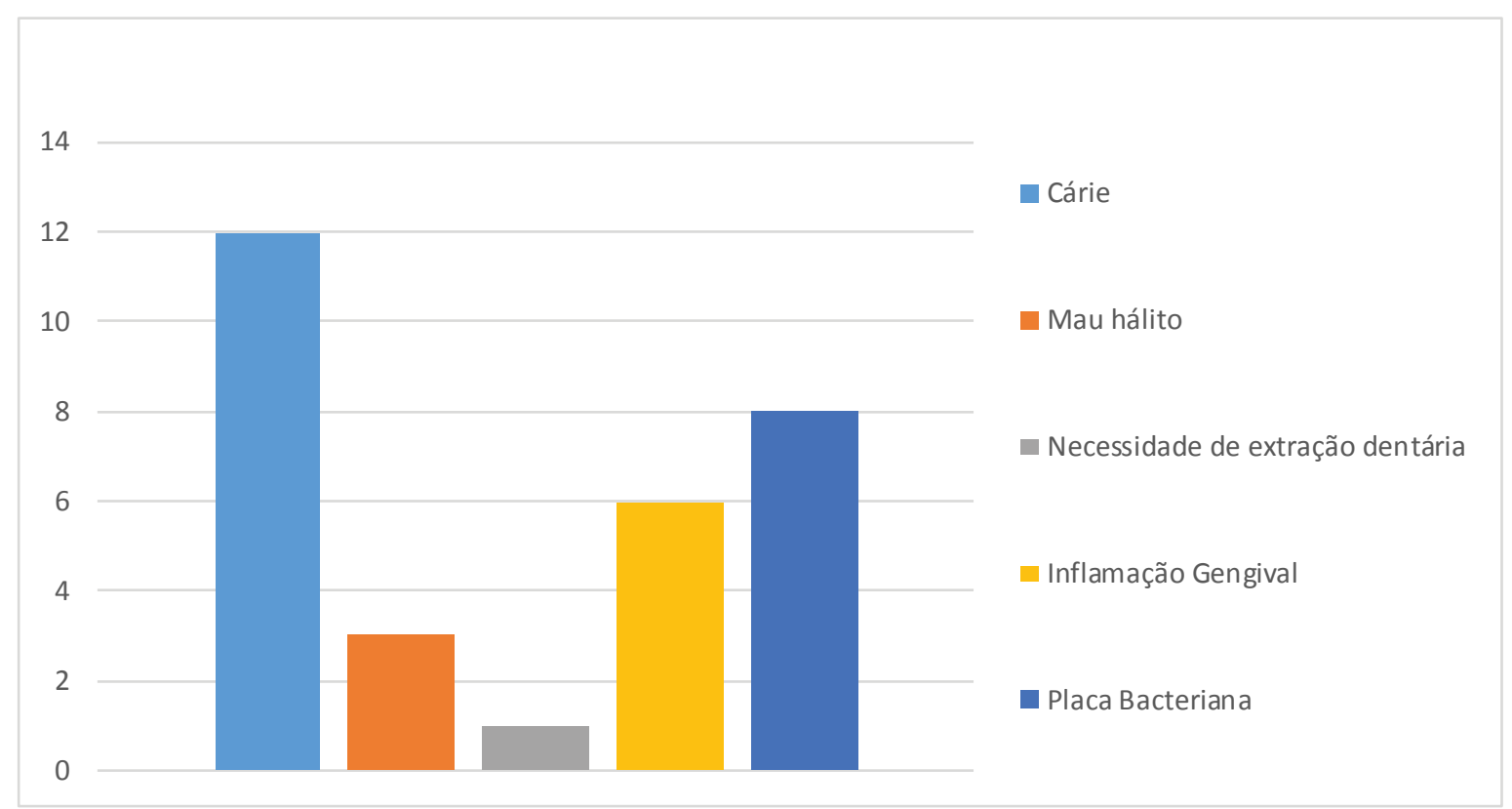

Figura 4: Problemas relacionados à má higienização oral, de acordo com mães e/ou cuidadores de PNE.

indisponibilidade de materiais e equipamentos especiais para facilitar e agilizar o tratamento proposto e que não estão disponíveis no serviço público. ${ }^{11,12,13}$

O presente estudo indicou que mais da metade das mães e/ou cuidadores auxiliam o(a) seu(ua) filho(a) durante a higienização oral e a realizam, numa frequência adequada. Contudo, os dados revelam que eles têm encontrado dificuldades relacionadas à escovação e ao uso do fio dental. Dados semelhantes foram observados por Soares, ${ }^{8}$ cujo estudo também revelou que os responsáveis muitas vezes não fazem esse cuidado pela dificuldade em aceitação do PNE devido às suas limitações. ${ }^{8}$ Figueiredo também demonstra que a maior dificuldade que os pais ou cuidadores têm, quando o aluno apresenta algum grau de limitação, é no uso do fio dental. ${ }^{10}$

A respeito do questionamento se os cuidadores participaram de palestras sobre a saúde bucal, a maioria dos respondentes já participou desse tipo de atividade. Isso pode ter contribuído para que $87 \%$ das mães e/ou cuidadores terem avaliado a saúde bucal de seus filhos como regular e ótima. Além disso, essa avaliação pode estar relacionada não somente ao fato da confiança dos cuidados prestados, mas também à constatação que $50 \%$ dos cuidadores alegarem levar os seus filhos a, pelo menos, duas consultas odontológicas no ano anterior.

Vale ressaltar que foi apontado por $36 \%$ dos entrevistados que para facilitar a manutenção de uma boa saúde oral seria necessário um maior número de centros especializados e de profissionais capacitados na rede pública. A necessidade de capacitar os profissionais da atenção básica e especializada, voltados para melhor recepção dessa demanda de paciente e suprir as necessidades do atendimento odontológico, foi também indicada como alternativa por outros pesquisadores. ${ }^{6}$

A demanda por atendimento odontológico é crescente no grupo de PNE, cabendo aqui ressaltar que a saúde bucal permeia um dos direitos fundamentais garantidos pela nossa Constituição. A falta de acessibilidade, 
divulgação, locais de atendimento, profissionais desinformados e sem comprometimento com a causa são apontados como fatores que contribuem para que o sistema público não consiga atender à demanda desse grupo populacional. $^{9}$

Apesar dos resultados positivos em relação ao conhecimento de mães e/ou cuidadores em relação à higienização oral do PNE, o nosso estudo aponta que ainda existem algumas lacunas a serem consideradas, no âmbito da prevenção e da promoção da saúde bucal. $\mathrm{Na}$ amostra analisada, mais de um terço dos cuidadores informou que realizou duas visitas (33\%), sendo valor semelhante observado para aqueles que fizeram, pelo menos, uma visita ao dentista (27\%). Contudo, houve aqueles (13\%) que não levaram o seu(ua) filho(a) a consulta odontológica alguma no ano anterior e aqueles que nunca participaram de qualquer atividade educativa ou treino para auxiliar o PNE com a higienização oral.

Cabe aos cirurgiões-dentistas responsáveis pelo atendimento estabelecer uma rotina que permita o atendimento das principais doenças bucais mais frequentes nessa população, a fim de ofertar serviços que considerem as limitações que cada patologia em si apresenta. Para tal, é preciso construir uma atuação integrada em diversas áreas, como enfermagem, medicina, fisioterapia, fonoaudiologia entre outras, construindo saberes que objetivem o bemestar dessa parte da população, que muitas vezes é esquecida ou negligenciada por parte dos governantes. ${ }^{14}$

A prevenção e a promoção da saúde, de modo geral, pressupõem investimentos em medidas que capacitem e instruam cuidadores, de uma forma orientada. Assim, a real implantação do Plano Nacional dos Direitos da Pessoa com Deficiência na rede de assistência pode contribuir significativamente para que equipes de Atenção Primária e os Centros de Especialidade Odontológicas possam atuar com os cuidadores, além de atender adequadamente ao PNE.

Um maior número de profissionais capacitados para 0 atendimento dessa população, principalmente na rede pública também, é alternativa interessante para que se possa avançar num atendimento mais equitativo para a população de PNE. A falta de estrutura física dos locais que prestam atendimento a essa população, o que termina por dificultar as idas e vindas desses pacientes aos serviços disponíveis, pode ser suplantada pelo atendimento de qualidade, pressupondo o princípio da equidade estabelecido pelo próprio SUS. ${ }^{15}$

\section{Considerações finais}

Mudanças na rede de atendimento ao PNE facilitariam a realização de uma manutenção da saúde oral. Isso demandaria uma adequação tanto do número de profissionais disponibilizados na rede pública, quanto como a provisão de materiais e instrumentos adequados para o atendimento a essa população. A prevenção e a promoção em saúde requerem investimentos maiores e adoção de medidas que auxiliem também na instrução dos cuidadores, orientando-os sobre os eventuais cuidados para a manutenção da saúde oral dos PNEs. Atuar de forma conjunta com os cuidadores é uma estratégia interessante e que pode contribuir de maneira significativa para a manutenção da saúde bucal dessa população.

\section{REFERÊNCIAS}

1. Brasil. Secretaria de Direitos Humanos da Presidência da República. Secretaria Nacional de Promoção dos Direitos da Pessoa com Deficiência. Coordenação-Geral do Sistema de Informações sobre a Pessoa com Deficiência. Cartilha do Censo 2010: pessoas com Deficiência. Brasília: SDH-PR/SNPD; 2012. 
http://www.pessoacomdeficiencia.gov.br/app/ publicacoes/cartilha-do-censo-2010-pessoascom-deficiencia

2. World Health Organization. Relatório mundial sobre a deficiência. The Word Bank; Traduções Lexicus Serviços Linguísticos. São Paulo: SEDPcD 2012: 334p.

https://apps.who.int/iris/bitstream/ handle/10665/44575/9788564047020_por. pdf?sequence $=4$

3. Vittorino GG, Souza GLN, Silva HMM, Marques EEM, Castilho LS de, Resende VLS. Atendimento odontológico a pacientes com necessidades especiais: treze anos promovendo sorrisos. Arq Em Odont., dez. 2011; 47: 12-5.

http://revodonto.bvsalud.org/scielo.php?pid $=S 151609392011000600002 \& \mathrm{script}=\mathrm{sci}$ arttext\&tlng $=p t$

4. Santos BMO, Aquino DJN, Pires-de Sousa FCP, Almeida GL, Garcia LFR. Assistência odontológica a portadores de necessidades especiais sob a ótica dos cuidadores. Ciênc Odontol Bras. 2009; 12 (2): 49-56.

http://ojs.ict.unesp.br/index.php/cob/article/ download/351/280

5. Resende VLS, Castilho LS, Viegas CMS, Soares MA. Fatores de risco para a cárie em dentes decíduos portadores de necessidades especiais. Pesq Bras Odontoped Clin Integr. 2007; 7 (2): 111-7.

https://www.redalyc.org/html/637/63770202/

6. Queiroz FS, Rodrigues MMLF, Junior GAC, Oliveira AB, Oliveira JD, Almeida E.R. Avaliação das condições de saúde bucal de Portadores de Necessidades Especiais. Rev Odontol UNESP 2014; 43 (6): 396-401.

http://host-article-assets.s3.amazonaws.com/ rou/588019cd7f8c9d0a098b534b/fulltext.pdf

7. Martins BR, Andia-Merlin R, Giovani ME. Avaliação sobre $a$ atenção com a saúde bucal de pacientes com necessidades especiais. Curso de Odontologia da Universidade Paulista, São Paulo- SP, Brasil, 2013; 31 (4): 360-67. https://www.unip.br/presencial/comunicacao/ publicacoes/ics/edicoes/2013/04_outdez/V31_ n4_2013_p360-367.pdf
8. Ferreira SH, Suita R.A, Rodrigues PH, Kramer PF. Percepção de estudantes de graduação em Odontologia frente ao atendimento de pessoas com deficiência. Revista da ABENO 2017; 17 (1): 87-96.

https://revabeno.emnuvens.com.br/revabeno/ article/view/367

9. Moraes ASM, Magna LA, Marques-deFaria AP. Prevenção da deficiência mental: conhecimento e percepção dos profissionais de saúde. Cad Saúde Pública. 2006; 22: 68590. http://www.scielo.br/scielo.php?script=sci_ arttext\&pid=S0102-311X2006000300023

10. Souza SP, Silva A., Guaré RO, Santos MTBR. Qualidade de Vida do Cuidador e Saúde Bucal do Indivíduo com Necessidade Especial. Pesq Bras Odontoped Clin Integr, João Pessoa, 11 (2): 257-262, abr./jun. 2011.

http://revista.uepb.edu.br/index.php/pboci/ article/viewFile/1441/682

11. Soares J., Volpato LER, Castro PHS, Lambert NA, Borges AH, Carvalhosa AA. Avaliação do conhecimento sobre saúde bucal de pais e cuidadores de crianças e adolescentes com deficiência. J Health Sci Inst. 2013; 31 (3): 239-43. https://www.unip. $\mathrm{br} / \mathrm{presencial/comunicacao/publicacoes/}$ ics/edicoes/2013/03_julset/V31_n3_2013_ p239a243.pdf

12. Campos CC, Frazão BB, Saddi GL, Morais LA, Ferreira MG, Setúbal PCO, et al. Manual prático para $o$ atendimento odontológico de pacientes com necessidades especiais, 2. ed. Goiânia: Universidade Federal de Goiânia; 2009.

https://odonto.ufg.br/up/133/o/Manual_ corrigido-.pdf

13. Braccialli, LMP, Bagagi, OS, Sankako NA, Araújo RCT. Qualidade de vida de cuidadores de pessoas com necessidades especiais. Revista Brasileira de Educação Especial, jan./mar. 2012; 18 (1): 113-126.

http://www.scielo.br/scielo.php?script=sci_arttext\& pid=S141365382012000100008\&lng=pt\&tIng=pt

14. Pini DM, Fröhlich PCGR, Rigo L. Avaliação da saúde bucal em pessoas com necessidades especiais. Faculdade Meridional, Passo Fundo, RS, Brasil. Einstein, 2016; 14 (4): 501-7. 
http://www.scielo.br/pdf/eins/v14n4/pt_16794508-eins-14-04-0501.pdf

15. Domingues NB, Ayres KM, Mariusso MR, Zuanon ACC, Giro EMA. Caracterização dos pacientes e procedimentos executados no serviço de atendimento a pacientes com necessidades especiais da Faculdade de Odontologia de Araraquara - UNESP. Rev Odontol UNESP 2015; 44 (6): 345-50. http://www.scielo.br/scielo.php?script=sci_arttext\& pid=S180725772015000600345\&lng=pt\&tlng=pt

Endereço para correspondência:

Gislaine Ribeiro de Oliveira Margon da Rocha gislainer@gmail.com

Submetido em:10-10-2018

Aceito em: 3-4-2019 